\title{
Formação de Professores em Informática Educativa na modalidade a distância: um relato de experiência do SENAC/EAD/RS
}

\author{
Ms Alexandra Lorandi Macedo1
}

Daiane Grassi2

\section{Resumo}

Este relato apresenta uma experiência de capacitação de professores para o uso da informática como ferramenta de apoio à educação. O mesmo está dividido em três subcapítulos, que no conjunto, tratam da apresentação, descrição, conteúdo e feedback dos alunos. O relato segue com indicação e perspectivas de práticas futuras, bem como referências.

Palavras-chaves: Informática na Educação, EAD, Formação Continuada

Formation of Professors in Educative Computer science in the modality in the distance: a story of experience of the SENAC/EAD/RS

\begin{abstract}
This work presents an experience of qualification of professors for the use of computer science as a tool of support to education. This document is divided in three sections about the presentation, description, content and feedback of the students. This report also presents indications and perspectives for future practises, as well as references.
\end{abstract}

Keywords: Computer science in the Education, EAD, Continued Formation

\section{Alfabetização Tecnológica e Informática na Educação}

Estamos no século XXI e a sociedade passa por grandes transformações, tanto em aspectos econômicos, financeiros, culturais e sociais como também educacionais. A exigência é um sistema educacional cada vez mais eficaz. $\mathrm{O}$ analfabetismo perdura ao longo dos anos e assume hoje uma gravidade maior, não só porque a evolução da sociedade já não aceita mais esse tipo de restrição ao exercício pleno da cidadania, as também, porque o dinamismo atual do mercado de trabalho requer trabalhadores com qualificação e capacidade de manejo das novas tecnologias.

Para Almeida (1987), a introdução da informática na educação deve ser percebida, levando em consideração o quadro de desenvolvimento e crise mundial. Na visão do autor, faz-se necessária uma nova reorganização das forças produtivas, sendo a informática mais uma etapa neste processo de divisão da força de trabalho a nível mundial. Quando se fala na inserção da informática na educação, em paralelo, levamse

1 Doutoranda em Informática na Educação (PGIE/UFRGS), Mestre em Educação (PPGEDU/UFRGS) e pesquisadora no NUTED (UFRGS).E-mail: alorandimacedo@gmail.com

2Especialista em Informática na Educação (CINTED/UFRGS), Pedagoga com habilitação em Multimeiose Informática na Educação (PUCRS). E-mail: daianegrassi @ yahoo.com 
em conta questões mundiais de produção, onde a educação tem um papel importante no desenvolvimento do capitalismo. A tecnologia no contexto educacional não deve ser tratada apenas como um processo de desenvolvimento natural, mas também, como o resultado de uma luta pela sobrevivência do mercado. No Brasil, a questão da informática relacionada com a educação já tem sua história (Moraes, 1995), apesar de poder ser ainda considerada como recente, já vem demonstrando sua presença tanto em nível de política pública como de uma prática pedagógica relacionada ao cotidiano de várias escolas.

Embora muitos considerem o computador e seus assessórios, em si mesmos, como ferramentas análogas ao lápis e ao livro, a grande maioria da população não sabe usálos nem conhece suas potencialidades e seus limites. A interatividade, a velocidade, $o$ complexo de relações e o dinamismo estabelecido entre seus componentes provocam, principalmente no adulto um estranhamento, o que, por sua vez acaba dificultando o processo de familiarização deste com a máquina.

$\mathrm{Na}$ educação, a cada dia que passa nos são apresentadas variadas metodologias, paradigmas e recursos tecnológicos que contribuem no processo de ensino e aprendizagem do aluno. Para tanto, o professor deve manter-se permanentemente atualizado sobre tais possibilidades e a maneira com que o mesmo possa utilizar estes recursos em prol da educação.

Destacando a utilização dos recursos tecnológicos na aprendizagem do aluno, enfatizase, a questão da informática como uma ferramenta de auxilio ao docente em suas práticas pedagógicas, do quanto é importante o uso deste recurso na educação. Segundo SOUZA e MANTORANI (2002):

O computador se tornou um excelente aliado do professor, não apenas no que se refere ao acesso à informação, mas também, no que diz respeito ao desenvolvimento da autonomia, da criticidade e da auto-estima do aluno. $\mathrm{O}$ aluno deixa de ser um mero receptor de informações e passa a ser responsável pela aquisição de seu conhecimento quando começa a usar o computador para buscar, selecionar e inter-relacionar informações significativas e, também, no momento em que passa a compor suas próprias idéias a partir do resultado de sua busca. (p. 47)

Contudo, para que de fato a utilização desta ferramenta como recurso didáticopedagógico se dê de forma adequada, mobilizadora, questionadora e desafiante é preciso preparar e sensibilizar o professor para que ele tire o melhor proveito desta tecnologia.

Envolver os professores nesse novo contexto é um grande desafio porque não se trata e ensiná-los somente a manusear a tecnologia, mas sim de indicar o caminho para um novo tipo de produção que pode ser gerada a partir da utilização da mesma no contexto Educacional Cysneiros (1997) alerta sobre o processo de adaptação da escola para o uso da tecnologia na educação. $\mathrm{O}$ autor destaca o posicionamento dos professores enquanto participantes ativos deste processo, para que, a partir disso consiga-se reverter os resultados insatisfatórios no uso na tecnologia na educação, em função da falta de capacitação docente.

\section{Relato de experiência}




\section{Caracterização do Curso Informática na Educação}

O curso de Informática na Educação, amparado pela Lei de Diretrizes e Bases da Educação - LDB no 9.394/96 que regulariza a oferta de cursos de formação inicial e continuada na modalidade a distância no SENAC/RS, caracteriza-se por ser um curso de Aperfeiçoamento. A categoria aperfeiçoamento, por sua vez, destina-se a profissionais que desejam uma complementação, atualização ou aprofundamento de competências que visam o seu desenvolvimento frente às mudanças constantes no mundo do trabalho.

Este curso foi organizado por uma equipe interdisciplinar, composta por Pedagogo MM/IE3, Especialista em Informática na Educação, Mestre em Educação, Publicitário Web Designer e Técnico em Informática. O mesmo foi pensado e desenvolvido para que de fato, os professores tivessem a oportunidade de experiênciar não só a utilização dos recursos tecnológicos na função de alunos, mas também a criação e gestão de projeto (enquanto educadores) utilizando a informática como recurso pedagógico.

$\mathrm{O}$ curso ocorreu inteiramente na modalidade on-line, sem encontros presenciais. Para tanto, foi utilizado o ambiente virtual de aprendizagem Moodle, como suporte didático, pedagógico e também tecnológico. Por ambiente virtual de aprendizagem, entende-se um local fechado na web em que o aluno entra e interage a partir do acesso de login e senha. Conforme FAGUNDES (2001 apud MACEDO 2005):

um ambiente virtual é entendido como um software desenvolvido para o gerenciamento da aprendizagem via WEB. É um sistema que integra a funcionalidade de um software para comunicação mediada pelo computador, além de um método de entrega de material de cursos on-line. (p.16).

$\mathrm{O}$ ambiente, além de ferramentas que possibilitam a comunicação e interação entre os sujeitos, comporta um conjunto de materiais composto por artigos, indicações bibliográficas, periódicos, revistas eletrônicas, animações entre outros, que servem como recurso para as reflexões e discussões realizadas. Estes recursos, denominados materiais pedagógicos, fazem parte das estratégias didáticas do tutor e foram construídos pela equipe interdisciplinar especializada da Instituição.

O público alvo atingido nesta primeira edição do curso foi principalmente professores entre 25 a 35 anos de idade, sob diversas áreas do conhecimento que, em sua maioria, possuíam conhecimentos básicos à intermediários, no que se refere ao manuseio técnico da informática.

A estruturação do curso foi organizada em quatro (4) componentes curriculares: módulo

1 - Introdução a Informática na Educação (10h), Módulo 2 - Práticas Pedagógicas I

(30h), Módulo 3 - Práticas Pedagógicas II (30h) e Módulo 4 - Projetos (10h).

Totalizando 80 horas de curso ao longo de três meses. A seguir, ilustração que identifica esta estrutura no ambiente virtual de aprendizagem:

${ }_{3}$ Pedagogo MM/IE corresponde a habilitação de Multimeios e Informática Educativa da Pedagogia 


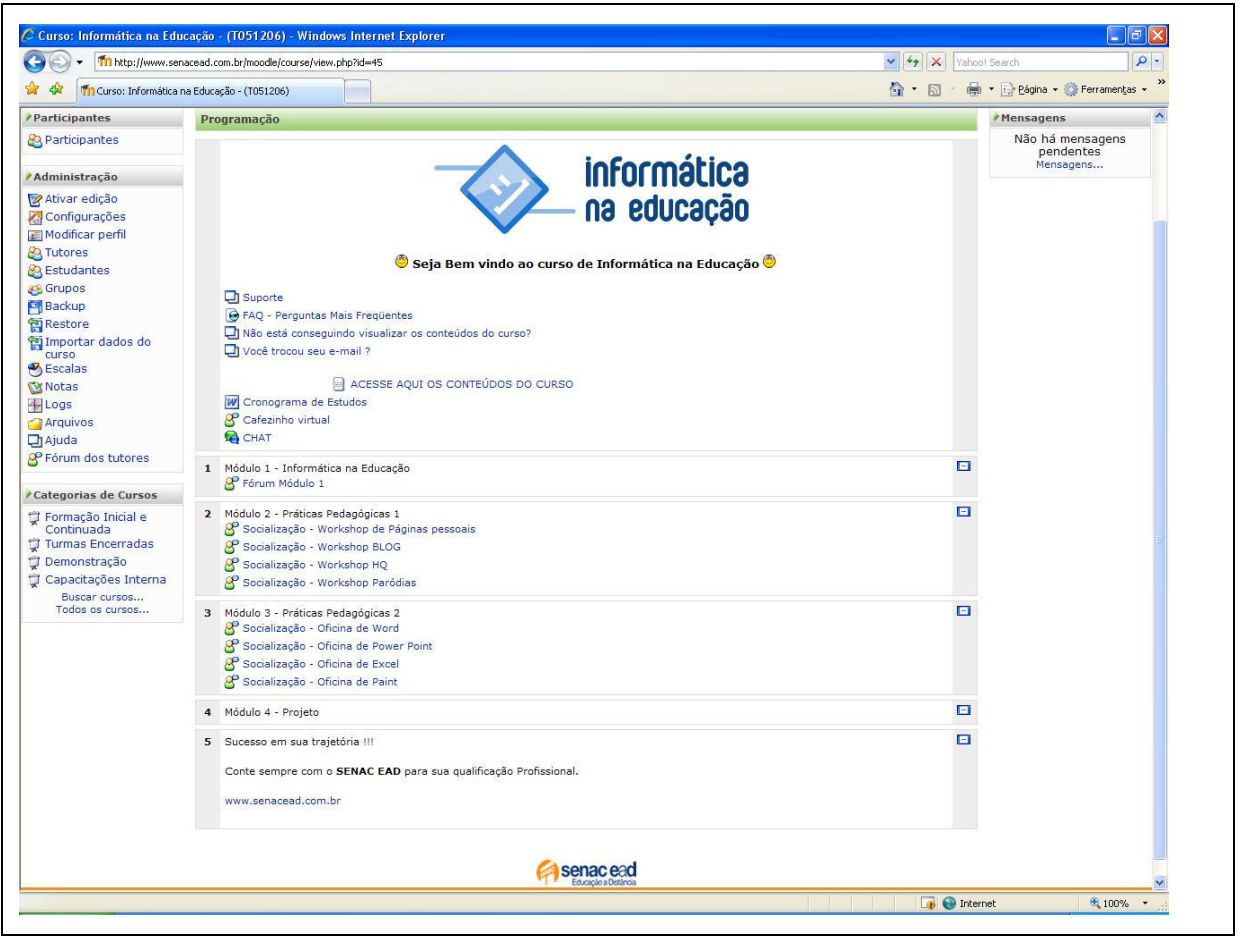

Figura 1: organização e estrutura do curso

No Módulo 1 - Introdução a Informática na Educação (10h) os alunos/professores foram convidados a refletir teoricamente sobre a utilização da informática como instrumento de auxílio na educação. Foi realizado um breve estudo sobre o cenário atual da informática educativa. Para tanto, criaram-se fóruns $4 \mathrm{em}$ que os alunos foram desafiados a desenvolver tais atividades:

1.1 Visite o site do MEC e verifique os projetos que estão sendo oferecidos em âmbito federal. Posicione-se criticamente no FÓRUM em relação a dois projetos, destacando a relevância dos mesmos.

1.2 Leia um dos artigos sugeridos, analise-o criticamente destacando aspectos positivos e negativos no texto.

1.3 Escolha a análise de um colega, postada no fórum, complementando-a com a sua visão.

No Módulo 2 - Práticas Pedagógicas I (30h) os alunos/professores foram desafiados a construírem suas páginas pessoais, contendo uma proposta de utilização pedagógica da mesma; a construírem seus BLOGS - diários eletrônicos - e a comentar os blogs dos colegas, estabelecendo uma rede de relacionamentos; a construírem

${ }_{4}$ Ferramenta de conversação e troca de materiais em tempo não real - assíncrono. 
histórias em quadrinhos, utilizando softwares específicos para isto e a construírem paródias educativas, utilizando também softwares especiais para esta função.

No Módulo 3 - Práticas Pedagógicas II (30h) foram oportunizadas aos alunos/professores a criação de estratégias pedagógicas utilizando as ferramentas de editores de texto, planilha, slides (apresentação) e desenho. Durante todo o desenvolvimento dessas atividades, os alunos/professores contaram com a disponibilização de materiais didáticos que embasavam as atividades, bem como a orientação de Tutores qualificados nesta área.

No Módulo 4 - Projetos (10h) foi proposto a construção de um projeto que utilizasse a informática como instrumento pedagógico. Para isto, foram respeitados os seguintes critérios: Introdução - Justificativa - Delimitação dos objetivos - Descrição da Proposta - Referencial teórico - Referencias Bibliográficas e Anexos.

O desenvolvimento deste módulo foi tão produtivo que surgiu a idéia da construção de um repositório de projetos acessível a todos os interessados.

Além dos módulos relatados, sempre esteve disponível um espaço para conversas informais, denominado "cafezinho virtual", um espaço para chats e o objeto virtual de aprendizagem (Figura 2). Este último, elaborado sob a metáfora de um computador animado, em que os alunos/professores encontravam todo o embasamento teórico e os desafios propostos no curso.

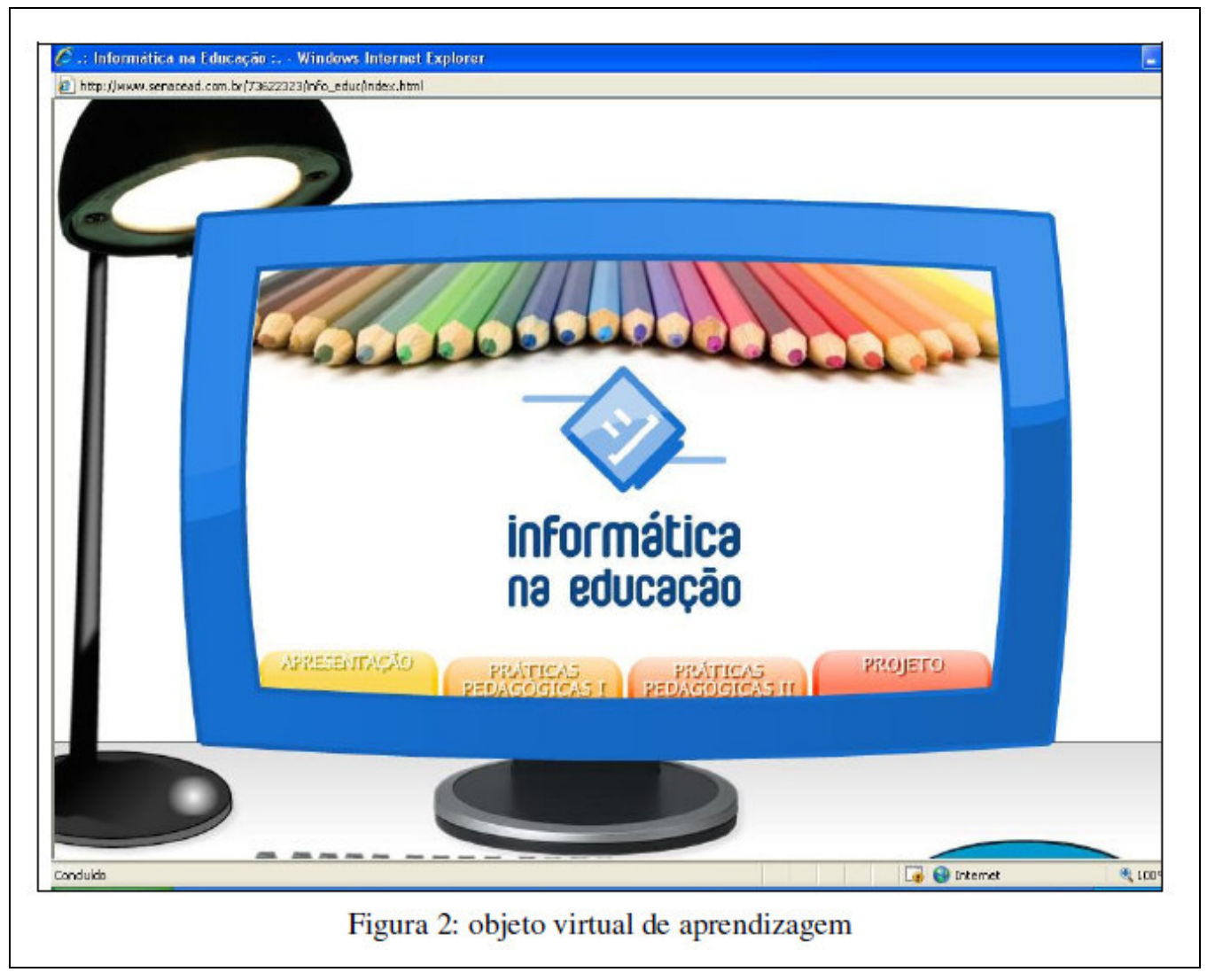

\section{Socializando projetos}

${ }_{5}$ Ferramenta de conversação em tempo real - síncrono 
Como último desafio proposto aos alunos/professores, foi realizado um momento de bate-papo síncrono com o grupo, cuja finalidade era a socialização dos projetos finais. Cada aluno postou o seu material no fórum acertado e dispôs de alguns minutos para apresentar aos colegas a sua proposta. Neste desafio, os alunos além de experiênciarem a utilização da ferramenta, fizeram intervenções, elogios e sugestões para o desenvolvimento dos trabalhos dos colegas.

Em decorrência desta atividade e dos belos trabalhos apresentados no curso, espertouse o interesse na Instituição em socializar e divulgar para a comunidade tais propostas.

Desta forma, foi criada a $1^{\text {a }}$ Semana Virtual de Práticas Pedagógicas em Informática a Educação do SENAC/EAD/RS. Esta, divulgada no site da Instituição, teve como objetivo potencializar reflexões sobre o uso da informática educativa, bem como apresentar as propostas criadas pelos alunos do referido curso.

\section{Perspectivas de continuidade}

A visão da continuidade do curso hoje é uma realidade. A utilização da informática na educação vem marcando o seu espaço e adquirindo adeptos no cenário atual. Após o recebimento dos retornos das avaliações de satisfação6 de nossos alunos/professores da primeira turma, foi possível identificar o quão importante é este trabalho de qualificação profissional. Dados como 95\% de satisfação e $98 \%$ de aplicabilidade dos conhecimentos e habilidades construídas nos fazem acreditar na importância que este curso representará na prática docente de nossos alunos. Estes mesmos dados nos fazem refletir em: porque não 100\%? Estratégias? Docência? Metodologia? Talvez sim, talvez não. O importante é deixar claro para a comunidade envolvida (professores e alunos) que todo o planejamento realizado é flexível à necessidade dos colaboradores. Estes que, muitos, no início pensavam na utilização do recurso, como fonte de treinamento, em poucos meses, no contato com indivíduos das várias áreas do conhecimento, já estavam com uma percepção de mudança, de aprendizagem, de construção do conhecimento.

Diante dessa perspectiva é que se pretende deixar esta proposta de aperfeiçoamento aberta e disponível no portfólio da Instituição. Com um olhar crítico, desafiador e tento às inovações tecnológicas é que este será acompanhado tanto por professores, como pela equipe pedagógica da Instituição e demais interessados na comunidade em colaborar e sugerir, como pesquisadores, estagiários e voluntariados.

\section{Referencial}

APPLE, Michael W. O computador na educação: parte da solução ou parte do problema? Revista Educação e Sociedade, no 23. São Paulo: Cortez,1986. ALMEIDA, Fernando José de. Educação e Informática. Os computadores na escola.

São Paulo: Cortez: Autores Associados, 1987.

COX, Kenia Kodel. Informática na Educação Escolar: Autores associados, 2003 coleção polêmicas do nosso tempo.

${ }_{6}$ Avaliação de satisfação de clientes é um procedimento adotado na Instituição para garantir a qualidade nos serviços oferecidos. 
CYSNEIROS, Paulo Gileno. A assimilação dos computadores pela escola. Mimeo, 1997.

DEMO, Pedro (1997). Pesquisa e Construção do Conhecimento: metodologia científica no caminho de Habermas. $3^{\text {a }}$ ed. Campinas, Autores Associados.

DURKHEIM, Emile. Educação e Sociologia. 9a ed. São Paulo: Melhoramentos, 1973.

FREIRE, F. P; PRADO, M.E.B.B.; MARTINS, M.C \& SIDERICOUDES, O. (1998). A implantação da Informática no espaço escolar: questões emergentes ao longo do processo". Revista Brasileira de Informática na Educação. Santa Catarina.

Lia Scholze, Salete Campos de Moraes [Org.]. Caderno temático: Multimeios e Informática Educativa - Porto Alegre: Secretaria Municipal de Educação de Porto

Alegre, 2002

MORAES, Raquel de Almeida. Educação, Informática e Sociedade: O Processo de Informatização do Ensino Público no Brasil. In VI Simpósio Brasileiro de

Informática na Educação. Belo Horizonte, 1995.

NÓVOA, Antônio; HUBERMAN, Michael; GOODSON, Ivor; HOLLY, Mary Louise, MOITA, Maria da Conceição; GONÇALVES, José Alberto; FONTOURA, Maria

Madalena; BEM-PERETZ, Miriam. Vidas de Professores. Porto Editora LTDA. 1992

OLIVEIRA, Ramon. Informática Educativa. São Paulo: Papirus, 1997.

PALLOFF, Rena; PRATT, Keith. Construindo Comunidades de Aprendizagem no Ciberespaço: estratégias para a sala de aula on-line. Porto Alegre: Artmed, 2002

PALLOFF, Rena; PRATT, Keith. O aluno virtual: um guia para trabalhar com estudantes on-line. Porto Alegre: Artmed, 2004

PERRENOUD, Philippe. Dez novas competências para ensinar. Porto Alegre: Artes Médicas Sul, 2000.

RHEINGOLD, H. (1996) A Comunidade Virtual. Lisboa: Editora Gradiva.

SARTORI, Ademilde Silveira; ROESLER, Jucimara Roesler. Comunidades Virtuais de Aprendizagem: espaços de desenvolvimento de socialidades, comunicação e cultura. In: Anais II Simpósio: E-agor@, professor? Para onde vamos? COMFILPUC- SP/COGEAE, 2003.

Salto Para o Futuro: TV e Informática na educação/ Secretaria de Educação a Distância. Brasília: Ministério da Educação e do Desporto, SEED, 1998.

VALENTE, José Armando. O Computador na Sociedade do Conhecimento. Campinas, SP: UNICAMP/ NIED, 1999. 